ORNL/TM-2020/1841

NN-18-1137

\title{
Comparison of Polymer AM Technologies for Automotive Tooling for Composite Engines
}

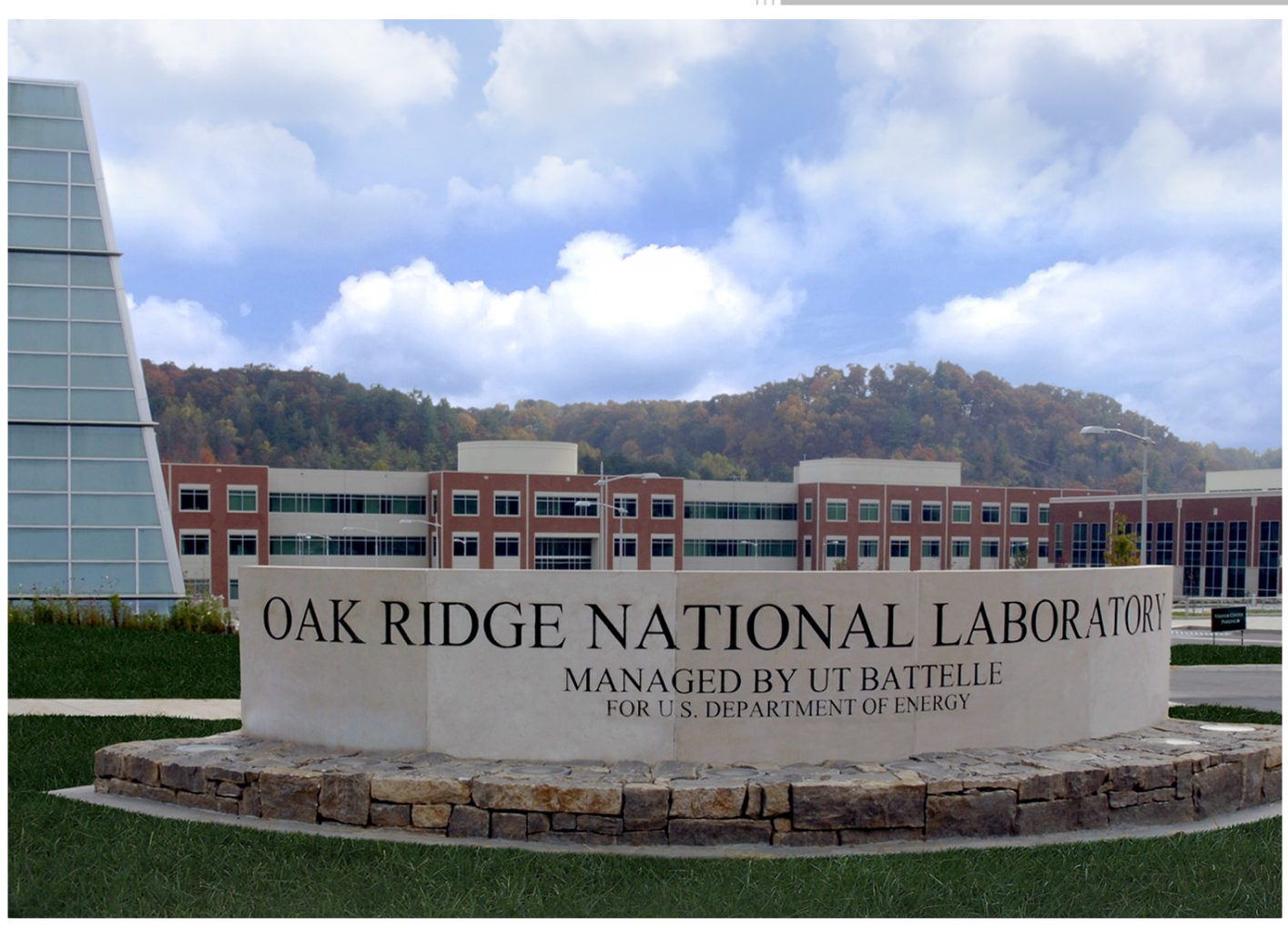

Phillip Chesser

Lonnie Love

Alex Boulger

Celeste Atkins

Andrew Rhodes

Matti Holtzberg

January 20, 2021

Approved for Public Release. Distribution is Unlimited.
USER AGREEMENT

FINAL REPORT NN-18-1137 


\title{
DOCUMENT AVAILABILITY
}

Reports produced after January 1, 1996, are generally available free via US Department of Energy (DOE) SciTech Connect.

Website www.osti.gov

Reports produced before January 1, 1996, may be purchased by members of the public from the following source:

\author{
National Technical Information Service \\ 5285 Port Royal Road \\ Springfield, VA 22161 \\ Telephone 703-605-6000 (1-800-553-6847) \\ TDD 703-487-4639 \\ Fax 703-605-6900 \\ E-mail info@ntis.gov \\ Website http://classic.ntis.gov/
}

Reports are available to DOE employees, DOE contractors, Energy Technology Data Exchange representatives, and International Nuclear Information System representatives from the following source:

Office of Scientific and Technical Information

PO Box 62

Oak Ridge, TN 37831

Telephone 865-576-8401

Fax 865-576-5728

E-mail reports@osti.gov

Website http://www.osti.gov/contact.html

\begin{abstract}
This report was prepared as an account of work sponsored by an agency of the United States Government. Neither the United States Government nor any agency thereof, nor any of their employees, makes any warranty, express or implied, or assumes any legal liability or responsibility for the accuracy, completeness, or usefulness of any information, apparatus, product, or process disclosed, or represents that its use would not infringe privately owned rights. Reference herein to any specific commercial product, process, or service by trade name, trademark, manufacturer, or otherwise, does not necessarily constitute or imply its endorsement, recommendation, or favoring by the United States Government or any agency thereof. The views and opinions of authors expressed herein do not necessarily state or reflect those of the United States Government or any agency thereof.
\end{abstract}


Energy and Transportation Science Division

Advanced Manufacturing Office

\title{
Comparison of Polymer AM Technologies for Automotive Tooling for Composite Engines
}

\author{
Authors \\ Lonnie Love \\ Phillip Chesser \\ Alex Boulger \\ Celeste Atkins \\ Matti Holtzberg
}

Date Published:

December 2020

\author{
Prepared by \\ OAK RIDGE NATIONAL LABORATORY \\ Oak Ridge, Tennessee 37831-6283 \\ managed by \\ UT-BATTELLE, LLC \\ for the \\ US DEPARTMENT OF ENERGY \\ under contract DE-AC05-00OR22725
}


Approved For Public Release 



\section{CONTENTS}

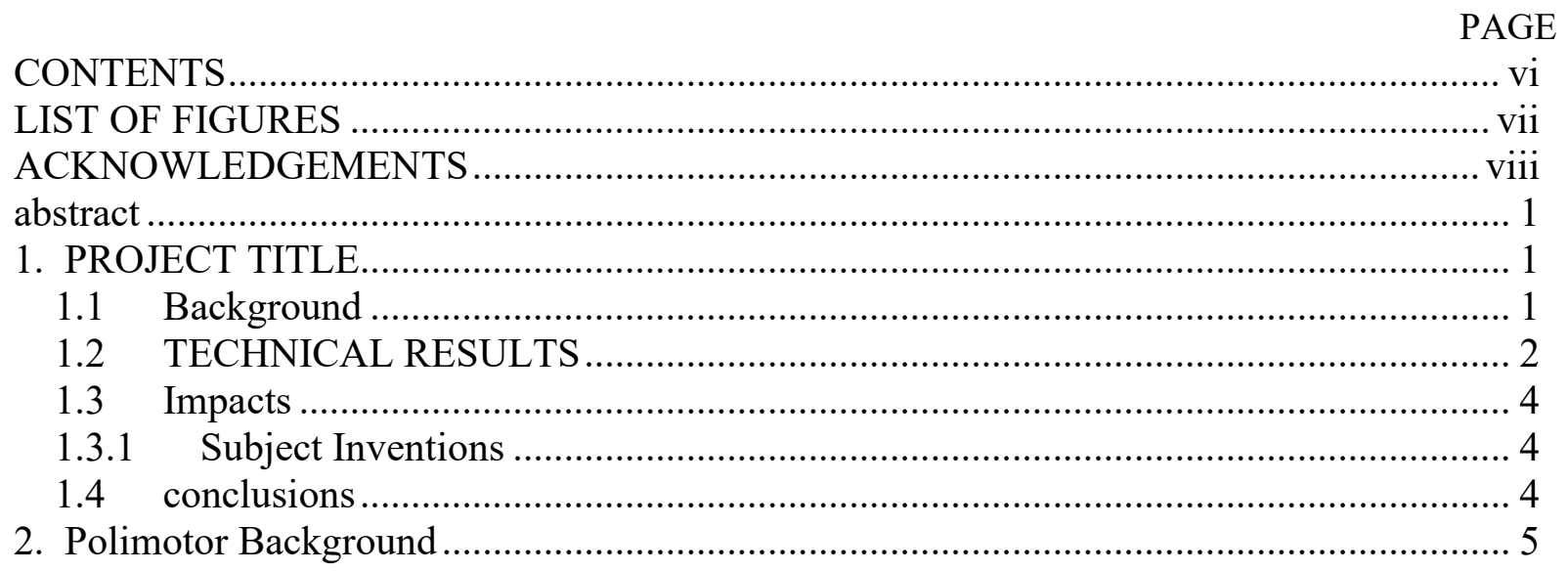




\section{LIST OF FIGURES}

Figure 1: Oil Pan Mold Geometry ............................................................................... 2

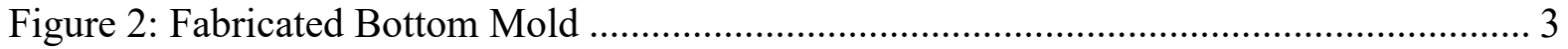

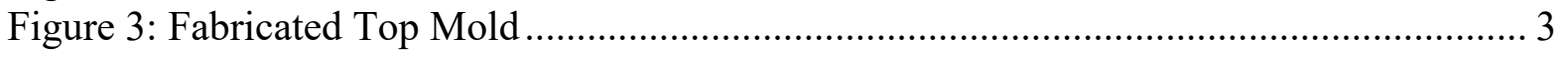

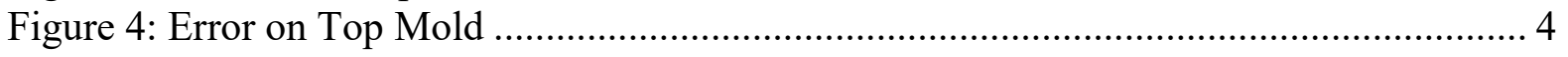




\section{ACKNOWLEDGEMENTS}

This user agreement NN-18-1137 was conducted as a Technical Collaboration project within the Oak Ridge National Laboratory (ORNL) Manufacturing Demonstration Facility (MDF) sponsored by the US Department of Energy Advanced Manufacturing Office (CPS Agreement Number 24761). Opportunities for MDF technical collaborations are listed in the announcement "Manufacturing Demonstration Facility Technology Collaborations for US Manufacturers in Advanced Manufacturing and Materials Technologies" posted at http://web.ornl.gov/sci/manufacturing/docs/FBO-ORNL-MDF-2013-2.pdf. The goal of technical collaborations is to engage industry partners to participate in short-term, collaborative projects within the Manufacturing Demonstration Facility (MDF) to assess applicability and of new energy efficient manufacturing technologies. Research sponsored by the U.S. Department of Energy, Office of Energy Efficiency and Renewable Energy, Advanced Manufacturing Office, under contract DE-AC0500OR22725 with UT-Battelle, LLC. 



\begin{abstract}
Oak Ridge National Laboratory's (ORNL) Manufacturing Demonstration Facility (MDF) worked with Polimotor to complete a set of molds for fabricating the oil pan for a composite engine. This project used multiple different AM processes to fabricate the mold set. The assembled parts were measured for tolerance and then sent to Polimotor to be used in the manufacture of engine components.
\end{abstract}

\title{
1. PROJECT TITLE
}

This user agreement (NN-18-1137) is with Polimotor. Polimotor is a small business. In this project molds were printed using a combination of additive manufacturing processes.

\subsection{BACKGROUND}

Holtzberg first started working on introducing plastics into automotive engines in 1969 when he tried to make polymer pistons for an Austin Mini engine in 1969. The pistons only ran 20 minutes before failing. Holtzberg added aluminum crowns to reinforce the pistons and sold them to racing engine builders.

Holtzberg was undeterred and in 1979 founded Polimotor Research Inc. with the goal of creating a racing engine mostly comprised of polymers. By 1984, Polimotor Research had developed a 168pound engine comprised of a plastic engine block, cam cover, air intake trumpets, intake valve stems, connecting rods, valve spring retainers and timing gears, among other things. Amoco Chemicals was the major funder of the effort, hoping to gain more publicity for its ground-breaking polymer, Torlon.

Holtzberg, who was granted 10 patents from 1983 to 1988 on composite engine parts and methods of production, put this engine in a Lola T616 HUO4 and competed in the International Motor Sports Association's Camel GT Championship series. The engine powered the car to several top five finishes, including a third place in the 1985 Lime Rock 2 hours in Connecticut.

The Polimotor received lots of attention from journalists at publications such as Automotive Industries and Popular Science but little from risk-averse automakers, and Holtzberg moved on to other ideas. In 1990, he founded Composite Castings LLC in Florida to develop carbon fiber composites. In 2011, Composite Castings introduced a carbon fiber composite four-cylinder engine block.

In 2015, Solvay approached Holtzberg, interested in working with him on new versions of the Polimotor. Solvay now owns and makes Torlon as well as other advanced polymers such as PEEK, Radel and Ryton. The manufacturing process with advanced polymers has come a long way. Parts that were cost-prohibitive in the 1980s are commonplace today and Solvay wants to show the world what advanced polymers can do.

The majority of Polimotor patents are for Polyamide-imide engine components, with the potential for graphite, glass or titanium reinforcement as a composite. The inventions are claimed to have a superior stiffness-to-weight ratio, be up to $70 \%$ lighter than traditional parts and reduce vibration and forces within the engine. The composite parts are also claimed to reduce production requirements due to being injection molded with consequently reduced finishing work.

Although the temperature, time and other process variables differ between parts, the general manufacturing process follows. The component is first injection molded and allowed to cool past its plastic deformation temperature. It is then post cured by solid state polymerization at a series of 
temperature steps. This is performed in an inert atmosphere which helps to expel by-products of reactions until the polymer is chemically stable. During this process the heat deflection temperature of the material also increases. The part is then cooled and post-processed. Post processing can take the form of machining, insertion or adhesion of metal parts or a simple cleaning of the part.

Currently, Polimotor is working with Ford on a prototype composite engine. The Polimotor composites use thermosetting resins that do not require high temperatures to melt like thermo plastics. Thus, tooling can be made from polymer. This opens the realm of polymer additive manufacturing for production of tooling. This project explored making tooling with additive manufacturing to mold components for Polimotor engines.

\subsection{TECHNICAL RESULTS}

The demands of the Polimotor molds produced in the project had unique challenges. It is well known that here is a tradeoff in additive manufacturing (AM) between build rates and resolution. If large parts must be printed fast, the resolution must decrease, while if parts must be printed at a high resolution, the build rate must decrease. The molds fall in an unfortunate position in between these two. High tolerances were required for the molding surface, but the size of the molds (1-2 ft on a side) was such that traditional small-scale fused deposition modeling (FDM) would not be able to produce molds large enough.

To deal with the size and tolerance constraints a hybrid approach was used to combine both small-scale and large-scale AM processes. The large bulk of the mold was printed with the Cincinnati Big Area Additive Manufacturing (BAAM) system out of $20 \%$ carbon fiber filled ABS. The detailed molding surfaces were printed on a Stratasys Fortus 900 out of Ultem 9085. Aluminum plates were used to hold the mold together.

The top and bottom halves of a mold for the oil pan of the engine were made. Figure 1 shows a CAD model of the oil pan mold geometry before optimization for printing.

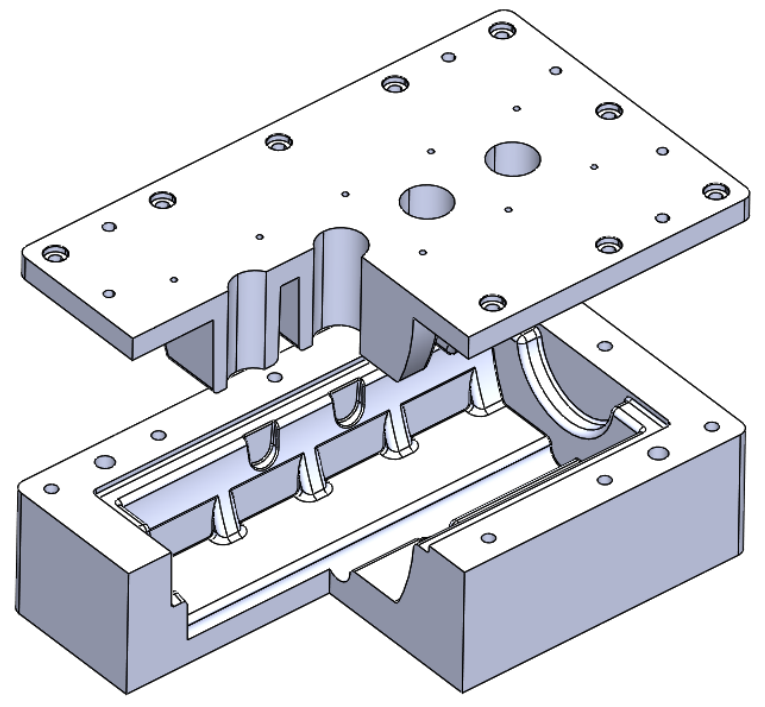

Figure 1: Oil Pan Mold Geometry

On the printed design, the interface between the two mold halves was made with aluminum plates. Additively manufactured components were then printed and attached to the plates. The bulk of the bottom mold was made with BAAM and an insert was printed on the Fortus 900 to make the molding surface. Figure 2 shows the fabricated bottom mold before and after assembly. 


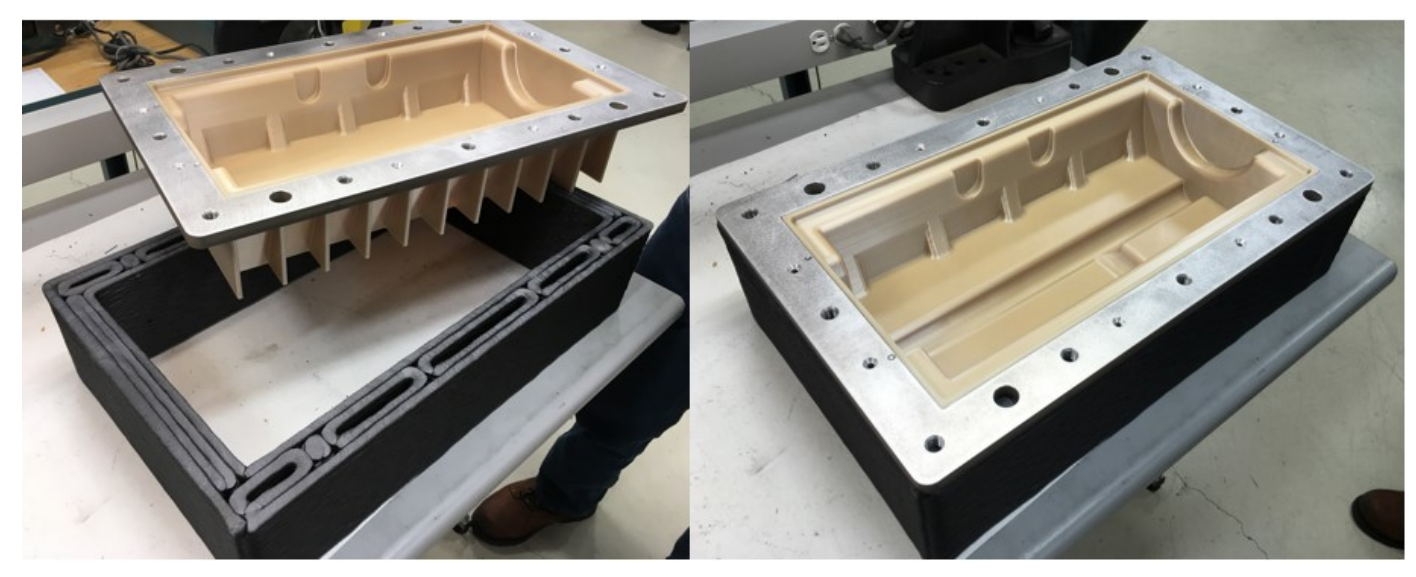

Figure 2: Fabricated Bottom Mold

For the top mold Fortus 900 parts were printed and attached to the plate to form the protruding molding surfaces. A BAAM part was not required on this mold. Figure 3 shows the fabricated top mold.

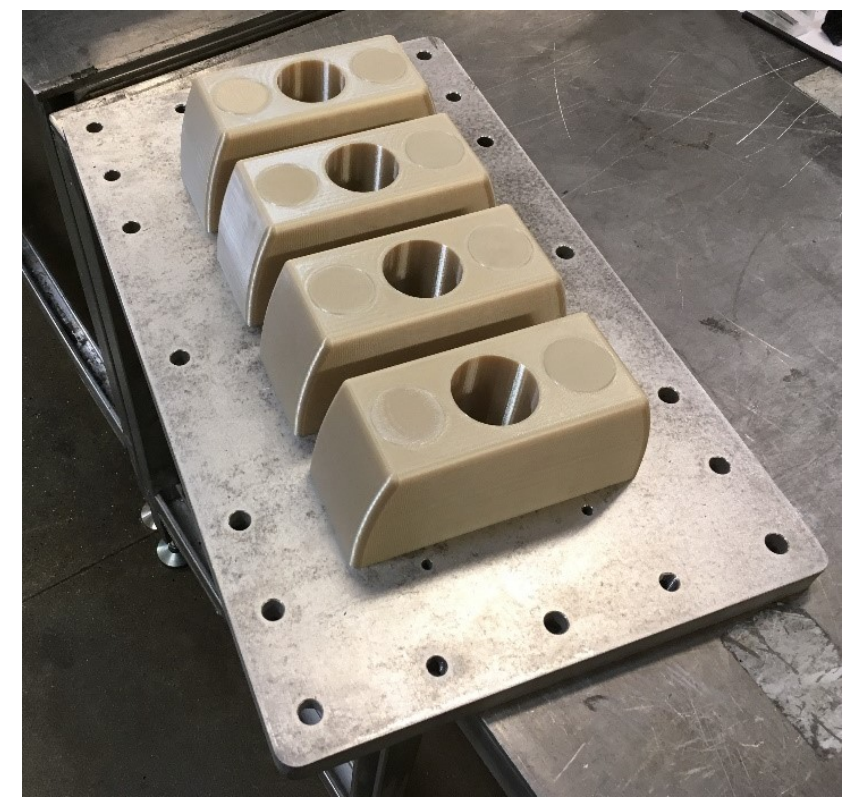

Figure 3: Fabricated Top Mold

In order to assess the accuracy of the final tool, a Leica AT960 laser tracker with a Leica LASXL scanner was used to scan the top mold. The measured points were compared with the CAD model using Verisurf measurement software. A heatmap showing error is shown in Figure 4. The average error was 0.003 inches, but some points were significantly further out. 

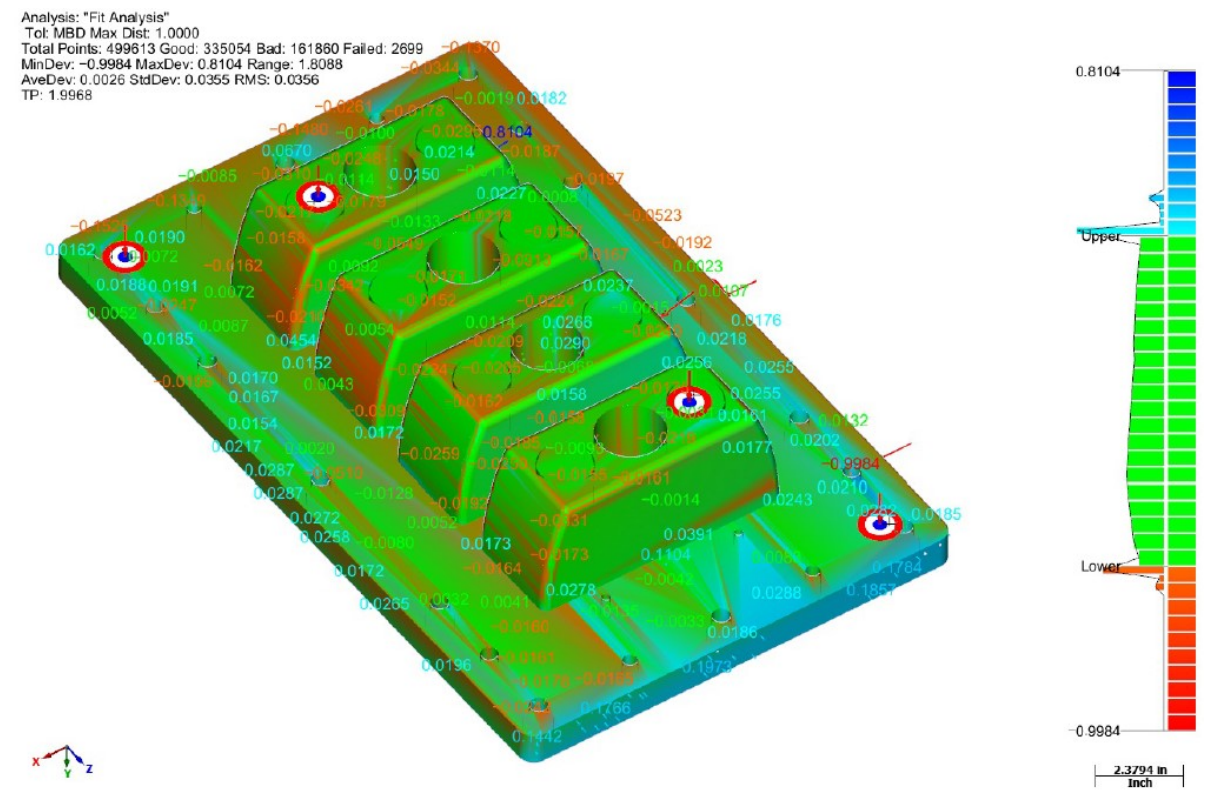

Figure 4: Error on Top Mold

In order to avoid having to print parts on multiple different AM systems and assemble them midscale thermoplastic AM processes were also investigated. A 3D Platform Workbench 400 series printer was used for this. The intention was to print entire mold sections on the Workbench 400, and then machine the mold to final tolerance. However, parts of the size needed for these molds could not be printed without significant warpage. Ultimately this path had to be abandoned because of warpage issues, leaving the hybrid approach described above.

\subsection{IMPACTS}

The molds were sent to Polimotor to support the development of an engine for Ford.

\subsubsection{SUBJECT INVENTIONS}

NA

\subsection{CONCLUSIONS}

The unique aspect of the project was using multiple AM processes to make a mold set. A single process was not able to meet the requirements of this mold, but by using multiple systems, the strengths of the different systems could be utilized. This project shows the power of using many different processes together in a way that plays to the strengths of each.

The completed molds were able to be used by Polimotor for engine fabrication. 


\section{POLIMOTOR BACKGROUND}

Polimotor is a small company exploring the use of composites to lightweight combustion engines. The Plastic automotive engine has its origins in the late 1970s with research and work done by Matthew (Matti) Holtzberg of Polimotor Research and his associates. Since then Holtzberg and others have done steady work in the field. Matti Holtzberg first attempted to make polymer pistons for an Austin Mini engine in 1969. The pistons ran for only 20 minutes until failure. Holtzberg remedied this by fitting the pistons with aluminum crowns and he sold these pistons to racing builders during the early 1970s. Throughout the 1980s, Holtzberg was granted 10 patents for composite engine parts and their methods of production. 